\title{
NUMERICAL ANALYSIS OF THE EFFECT OF NONMETALLIC INCLUSIONSLOCATION IN CARBURIZED LAYER OF 16MNCR5 STEEL ON INITIATION OF FATIGUE CRACKING
}

\author{
Sebastian Lipa ${ }^{1}$ \\ 1 Institute of Materials Science and Engineering, Lodz University of Technology, Stefanowskiego 1/15, 90-924 \\ Lodz, Poland, e-mail: sebastian.lipa@p.lodz.pl
}

Received: 2018.01.16 Accepted: 2018.08.08 Published: 2018.09.01

\begin{abstract}
This paper presents the results of a numerical analysis of the effect of the position of non-metallic inclusions in a hardened top layer in $16 \mathrm{MnCr} 5$ steel on the mechanism of fatigue destruction. An analysis of a hardened layer formed by thermo-chemical treatment using FineCarb ${ }^{\circledR}$ technology was conducted.Non-metallic inclusions formed by deoxidation of steel were studied; they are usually made of calcium and aluminum. Four positions of inclusions in the hardened layer were tested: under the layer, in the middle part of the layer, under the surface and on the border of two sublayers. The results of the FEM analysis were treated as a qualitative analysis. A map of plastic strains around the inclusion under study was observed. The appearance of plastic strains in the area under analysis signaledthe initiation of a fatigue crack. It was observed that the mechanism of destruction depends largely on the distribution of stress in the top layer and on the place where the inclusion is anchored in the layer. Inclusions under the layer were found to be the main cause of the loss of the structural continuity, which explains the most frequent cases of the initiation of fatigue cracks.
\end{abstract}

Keywords: non-metallic inclusions, fatigue, thermo-chemical treatment, FEM simulations.

\section{INTRODUCTION}

A continuously growing interest in materials with good strength properties, including fatigue strength, necessitates not only seeking of new alloys for thermo-chemicaltreatment, but also exploring mechanisms of destruction of such materials by external load $[5,13]$. The majority of loads which can shorten the "life time" of a product are cyclically variable loads. They are dangerous as they cause stress in the structure, which leads to its destruction without exceeding the momentary strength of a material. The concept of fatigue strength is generally known, both in the literature and in technology, but it is hardly predictable. It is affected by the structure, material, as well as conditions of use. Fatigue strength can be increased by such measures as, for example, modifications of materials. Such modifications are made by plastic working (die forging), thermal treatment (surface hardening), choice of the optimum chemical composition (alloying)and thermo-chemical treatment (carburizing). One of such methods of steel treatment is LPC (Low-Pressure Carburizing) technology [7], whose effect has been demonstrated in several papers $[3,15]$. Achieving the optimum parameters in the process increased the fatigue strength $[1,2,6]$ compared to conventional (gas quenching) technology [4]. The LPC technology eliminates internal oxidation, which prevents the formation of surface notches. It is the surface notches that are often a potential source of initiation and development of fatigue cracks. Additionally, the cleanliness and smoothness of the surface after the treatment carried out made polishing in the final stage unnecessary. Polish- 
ing in conventional thermo-chemical treatment is known [14] to introduce elongation stress into the layer, which - in the case of a cyclic load - may result in decreasing the fatigue strength. A number of researchers have noted that fatigue strength is affected by internal defects of the material, inclusions, including non-metallic ones [17, 18], pores, grain size in the material structure etc. They have shown [20] that the fine-grain structure and alloy purity increases the fatigue strength. The smaller the grains in the material structure, the greater the momentary strength of alloys. Theseresults in greater cycle-load strength [11]. For example, Z.G. Yang et al. [21] observed the effect of the size of inclusions in high-strength alloys subjected to thermal treatment. The grain size and inclusion size was examined. Furthermore, the role of residual austenite was noted. The authors showed the thermal treatment process to have a crucial effect on the increase or decrease in fatigue strength. The size of frontal inclusions in a specimen was determined; they initiated a fatigue crack. It was demonstrated in $[9,22]$ that the presence of large non-metallic inclusions which form during steel deoxidation results in a sudden drop in fatigue strength. Such inclusions often have a crucial effect on the mechanism of initiation of a fatigue crack, especially in the area close to infinite fatigue strength or with a high-frequency load $[8,12,19]$. The mechanism of fatigue destruction has usually been explained by the formation of so-called fisheye, where hydrogen trapped around a non-metallic inclusion caused local decohesion at the border of two different phases [10, 15, 21]. Therefore, phenomena around inclusions have been seen as one of the major causes of the loss of integrity of structure as a result of a cyclically varying load.

As it was stated before, the presence of nonmetallic inclusions is caused by deoxidation of steel in the process of continuous casting. The addition of aluminum oxides and calcium reduces the amount of oxygen and allows controlling and modifying physicochemical properties of non-metallic precipitates. Usually, products as two-component calcium aluminate molecules $\mathrm{mCaO} * \mathrm{nAl}_{2} \mathrm{O}_{3}$, cause reduction of the effect of solidification of ingots. Therefore, the presence of non-metallic inclusions is dependent on the steel production technology.

To complete presented state of the art, it is justified to use numerical methods to examine the influence of non-metallic inclusions location in correlation to stress distribution in the hardened layer as a factor affecting fatigue strength of steel after LPC treatment. As a consequence of performed research, the possible nucleation and fatigue crack propagation mechanisms previously observed by i.a. K. Dybowski and the co-authors of the article cited $[2,6]$ were explained. Taking into consideration the results of fatigue tests on $16 \mathrm{MnCr} 5$ steel after LPC treatment and the main cause of the loss of cohesion under cycle loading, i.e. non-metallic inclusions based on calcium and aluminum presented in papers $[8,9,19,22]$, the numerical model in ANSYS 18.0 environment was created. Original FEM model was complemented with a couple of possible positions of non-metallic inclusion in the technological surface layer.Based on observations of yield stress distribution around the inclusion, the possible crack initiation sited were sought after.

\section{STUDY METHODOLOGY}

\section{Hardened top layer}

The numerical model presented in this paper is based on the results of a study of hardened top layers formed in the FineCarb ${ }^{\circledR}$ technology described in the paper by K. Dybowski and coworkers [2]. The specimen was made from popular and widely used $16 \mathrm{MnCr} 5$ steelfor thermochemical treatment, whose chemical composition is shown in Table 1.This steel is used for machine elements such as gears, pivot, roller, etc., that work with cyclic bending loads.

Tests were conducted on a technological top layer in which the parameters of low-pressure carburizing (LPC) of steel were chosenso as to obtain the effective case depth of $0.6 \mathrm{~mm}$ for the $0.40 \% \mathrm{C}$ criterion. Carburizing was conducted at a temperature of $920^{\circ} \mathrm{C}$ for $90 \mathrm{~min}$. The process

Table 1. Chemical composition of $16 \mathrm{MnCr} 5$ steel according to PN-EN 10084

\begin{tabular}{|c|c|c|c|c|c|c|c|c|}
\hline $\mathbf{C}$ & $\mathbf{S i}$ & $\mathbf{M n}$ & $\mathbf{C r}$ & $\mathbf{N i}$ & $\mathbf{W}$ & $\mathbf{S}$ & \multicolumn{1}{|c|}{$\mathbf{P}$} & $\mathbf{F e}$ \\
\hline $0.14-0.19$ & Max 0.4 & $1.0-1.3$ & $0.8-1.1$ & Max. 0.3 & Max. 0.2 & Max. 0.035 & Max. 0.035 & Bal. \\
\hline
\end{tabular}




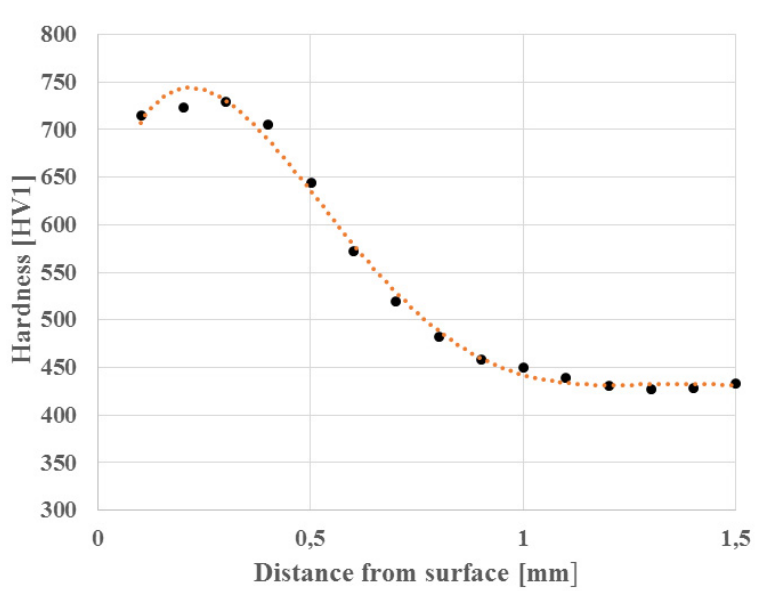

Fig. 1. Microhardness profiles of $16 \mathrm{MnCr} 5$ steel after low pressure carburizing with hardening [2]

was carried out in a vacuum carburizing furnace VPT-4022/24IQN with the HPGQ option. The carburizing atmosphere was a mixture of hydrocarbons: acetylene and ethylene (1:1) diluted with hydrogen. Quenching was carried out in nitrogen at a pressure of $1.2 \mathrm{MPa}$ with cooling down to $860^{\circ} \mathrm{C}$. Tampering was conducted at a temperature of $180^{\circ} \mathrm{C}$ for 2 hours in order to reduce quenching stress. Thus, the prepared top layer was subjected to microhardness and diffractometry tests. The results are shown in Fig. 1 and 2.

In order to determine the shape of a nonmetallic inclusion, the analysis was based on the results of "free-end" resonance fatigue tests, described in a paper by K. Dybowski et al. [2]. A 44 $\mu \mathrm{m}$ spherical inclusion, observed by the authors of this paper, was taken for numerical analyses (Fig. 3a).The chemical composition of non - metallic inclusion presented in figure $3 \mathrm{a}$ was determined with the use of the JEOL JSM-6610LV

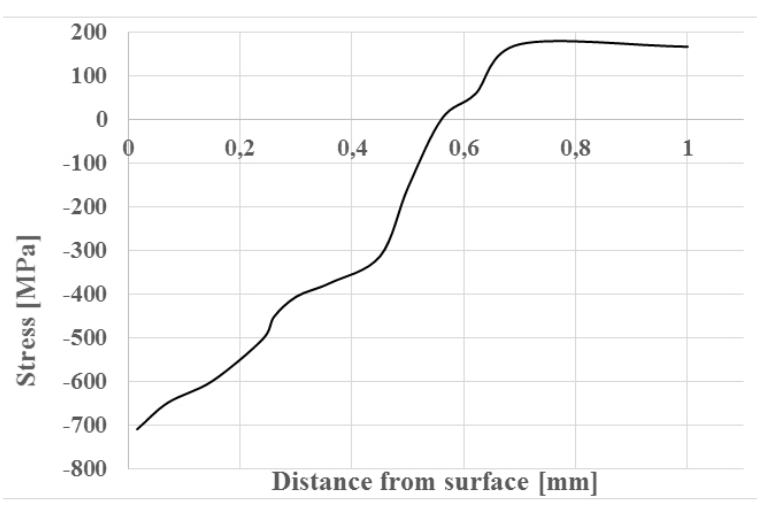

Fig. 2. Distribution of strain in a hardened layer formed as a result of thermo-chemical treatment [2] a)
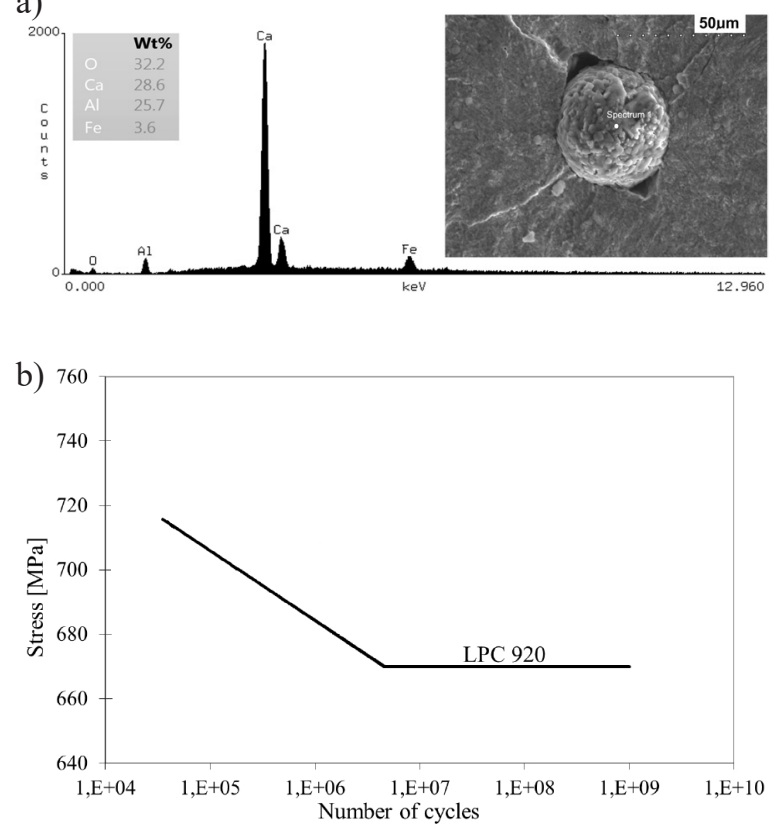

Fig. 3. a) A scanning microscopic image of a non-metallic inclusion in the area of a fatigue crack initiation and X-ray microanalysis of a fatigue center formed during a test conducted by the resonance method of a specimen of $16 \mathrm{MnCr} 5$ steel, b) Fatigue bending strength $16 \mathrm{MnCr} 5$ steel (Wöhler curve) following low-pressure carburizing in the FineCarb ${ }^{\circledR}$ technology

scanning microscope. In the work, EDX method in the Oxford Analysis system equipped with XMAX 80 EDS detectorwas used. The analysis was made on the surface of the inclusion shown in Fig. 3a. The example of Wöhler curve for $16 \mathrm{MnCr} 5$ steel for limited and unlimited fatigue strength was shown in Fig. $3 b$.

\section{Assumptions for a numerical model}

A beam loaded with three-point bending was tested in this study and the loads corresponded to variable unilateral forcing, such as in fatigue strength tests. It must be mentioned that the beam was placed on its ends, on articulated moveable supports. Therefore, a perpendicular force going through the beam axis was the only reaction on the supports. A flat 2D model was analyzed. Therefore, a case was analyzed in which the loads are in the same plane as the lines of deflection of the strained specimen. Only the stress in the X-X longitudinal direction of the beam were taken into account in order to reproduce the distribution of stress in the hardened layer. Stress along the other axes were disregarded as less important to the 
qualitative analysis. A uniform triangular distribution was taken for calculations of displacement in the proposed method, with the stress equal to zero on the neutral axis in pure bending. It corresponded to the uniform distribution of bending stress in the beam with elastic strain of the material. Therefore, the plastic stress in a global sense was not exceeded. At the same time, the analysis allows exceeding the plastic strain around nonmetallic inclusions as a result of superposition of the distribution of bending stress, with the distribution of stress in the top layer.

\section{Numerical model}

A numerical model of a non-metallic inclusion was based on the distribution of displacements of the hardened layer and the core in the $\mathrm{X}-\mathrm{X}$ axis of the bent beam so as to achieve elongation stress (lower fibers of the beam) and compression stress (upper fibers of the beam) on the cross section in its central part (Fig. 4). The beam was $7 \mathrm{~mm}$ tall and the thickness of the hardened layer was estimated at $0.6 \mathrm{~mm}$. The layer hardened by TCT (Thermo - Chemical Treatment)was modeled in such a way as to generate seven $0.1 \mathrm{~mm}$ sublayers (Fig. 4). For each of these sublayers, a material was allocated taking into account a change of compressing or elongating stress corresponding to the distribution of stress in the hardened layer (Fig. 2) (from $-700 \mathrm{MPa}$ to $+167 \mathrm{MPa}$ core). Additionally, a non-linear material was introduced to the bi-linear FEM and a change in the yield limit of each of the sublayers was taken into account on the basis of a change of hardness as a function of carbon content. Input data for the FEM analysis, i.e. stress distribution, was taken from the test results (Fig. 2). The hardness distribution as in Fig. 1 was adopted to determine the mechanical properties of the hardened layer and the core. Therefore, it was necessary to convert hardness to the yield limit and strength. It was done with the JMATpro module by determining the Young module and the mean hardness in the area of interest. This enabled us to generate the stress-strain graph for the material in the cases under study, which is shown in Fig. 5.

The FEM model was mentally divided to separate each sublayerand only a small "section" of a sublayer with an inclusion was taken for further analysis. In order to determine the boundary conditions for the FEM analysis, so-called forcing by displacement, a change of a sublayer displacement in the $\mathrm{X}-\mathrm{X}$ axis was calculated adopting the beam bending load in the elastic area. The rationale behind this approach involved a simulation of the variable fatigue load which, in general, occur in the elastic area of the material, i.e. they do not exceed the yield limit (fatigue strength is always estimated below the yield limit). The basic displacement was the core displacement (case 1) in which "starting" plasticizing strain of the core around an inclusion was achieved.

Numerical analyses were conducted by means of the Anysys 18.0 software. The model was created from PLANE 183 type elements with

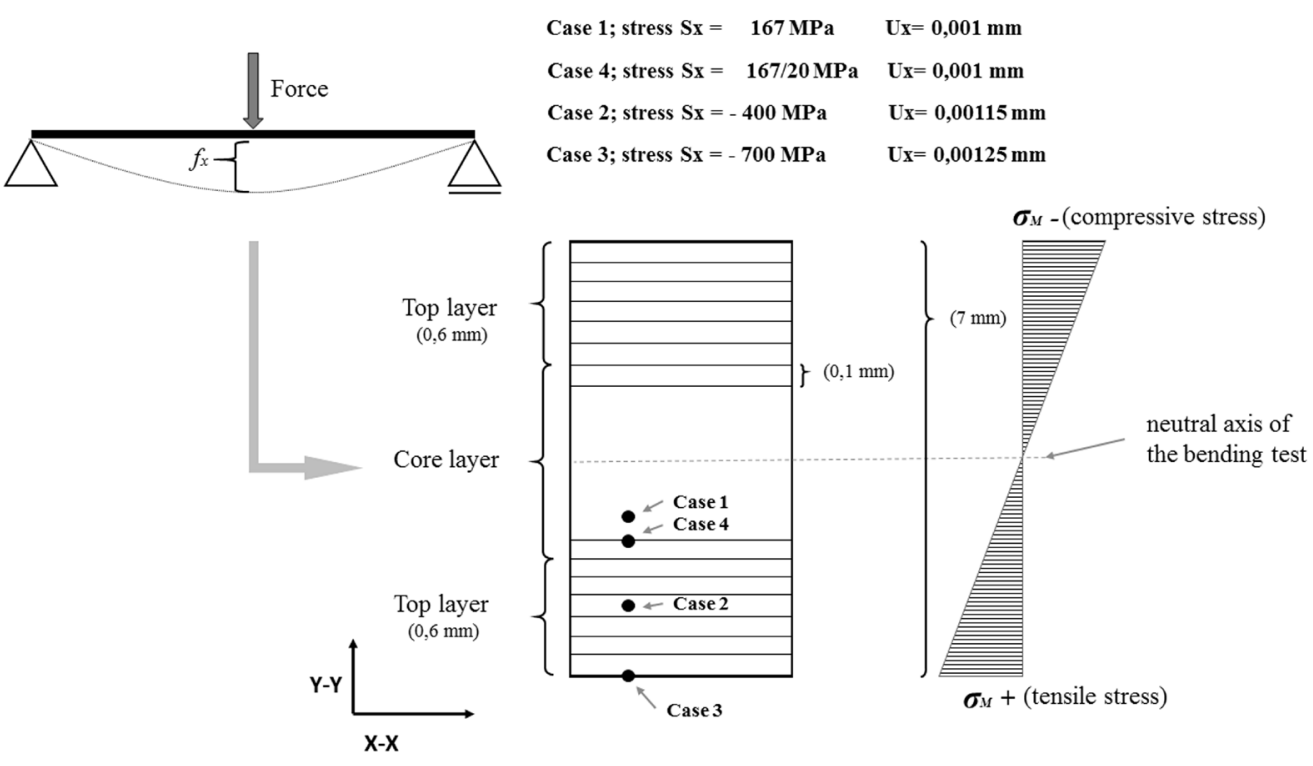

Fig. 4. An approximated model of the bent beam andof the structure of the hardened layer and its division into sublayers 


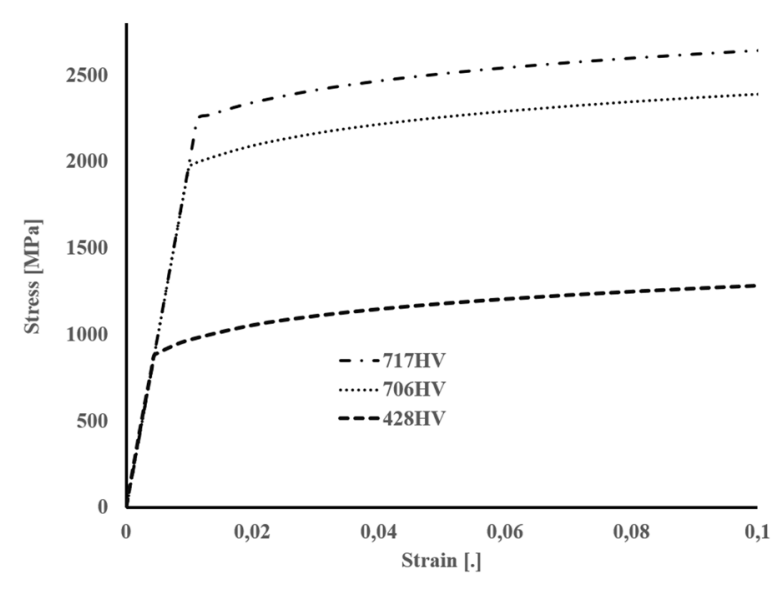

Fig. 5. The stress-strain graph estimated from the hardness distribution for the cases under analysis

a discretization of 0.001 . The conditions of the contact between inclusion and the core were not taken into account in the numerical model. The numerical grid of the inclusion and the core was connected with nodes with the "GLUE" function.

\section{NUMERICAL ANALYSISOF THE FIELD OF STRAIN AROUND A NON-METALLIC INCLUSION}

\section{Case 1 - inclusion in the core}

The whole method is based on the observation of the behavior of a non-metallic inclusion in the core. The area in which plastic strains occurred at the assumed initial conditions of the analysis was chosen as the place of potential initiation. Based on literature reports, non-metallic inclusion with aluminum and calcium in their composition have strength properties such as yield strength much smaller than their matrix (core) in which they are anchored. Therefore the first stage involved an analysis of an inclusion with the yield limit 50\% lower than that of the core. The Young module and the Poisson number was the same as that in the core, i.e. $200 \mathrm{GPa} v=0.3$. This approach to the analysis increased the sensitivity of calculations to the changes around an inclusion. An increase or decrease in the yield limit of the inclusion itself mainly changed the displacement along the $\mathrm{X}-\mathrm{X}$ axis for which a plastic strain was achieved in the observed area at a specific moment. Therefore, the inclusion was plasticized faster than the core. The analysis was qualitative in which the area around the inclusion was observed and its behavior as affected by load. The graph presented in
Fig. 2 shows that the core (under the layer) situated at a distance of $0.8 \mathrm{~mm}$ from the specimen surface is stretched by a stress of $+167 \mathrm{MPa}$. Its yield limit, which arises indirectly from the hardness distribution, is estimated to be $1054 \mathrm{MPa}$.

First, the minimum displacement along the $\mathrm{X}=\mathrm{X}$ axis of the model of a "section" of the core situated at a distance of $0.8 \mathrm{~mm}$ from the surface.

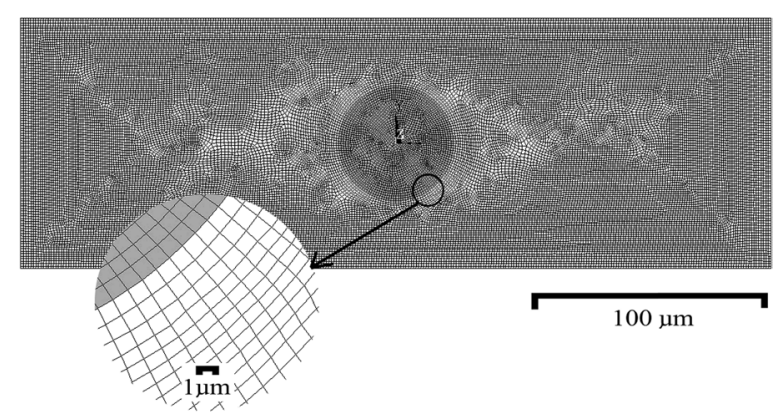

Fig. 6. Numerical model of inclusion on the core
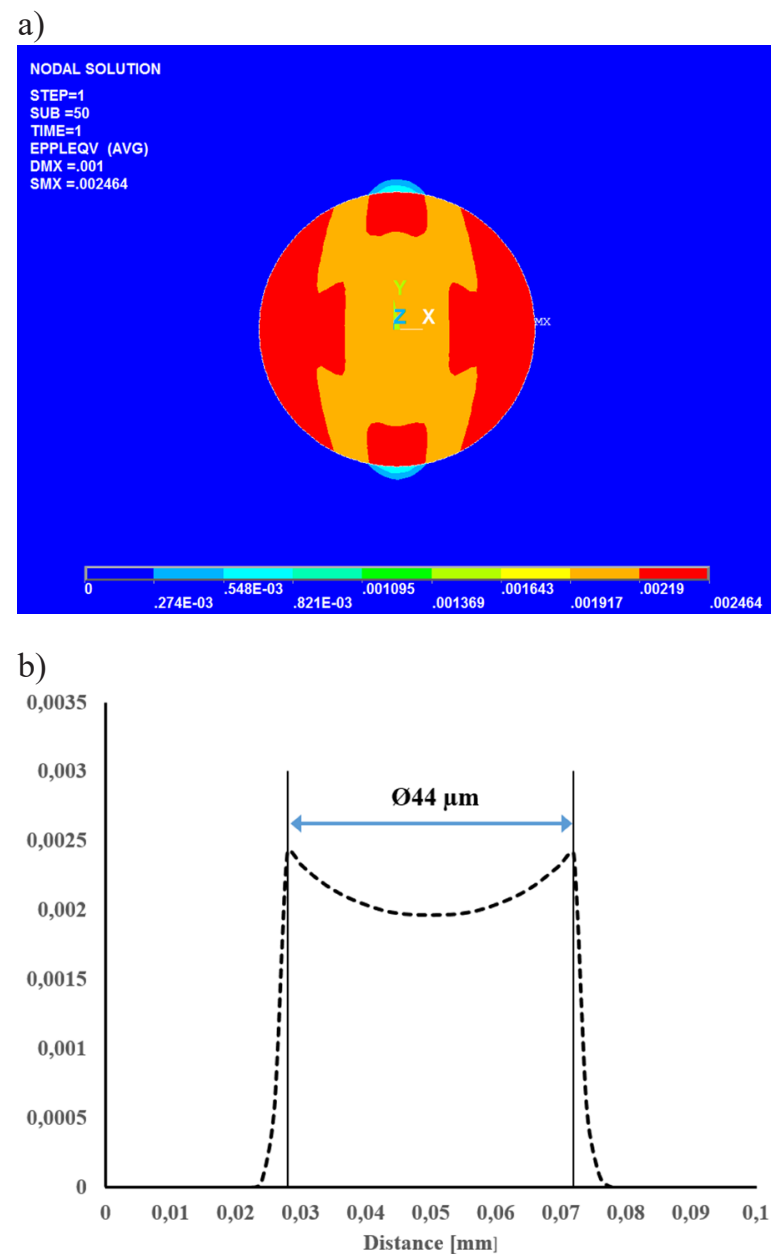

Fig. 7. a) A map of plasticizing strainsaround the inclusion case 1, b) a graph of plasticizing strains as a function of distance from the surface (a diameter of inclusion is determined) 
The observed area was limited to a $0.3 \times 0.1 \mathrm{~mm}$ rectangle. An $44 \mu \mathrm{m}$ inclusion was introduced to the model. Geometric and physical non-linearity was used in the analysis restricting the material with a yield limit of $\mathrm{Re}=1054 \mathrm{MPa}$ for the core and $604 \mathrm{MPa}$ for the inclusion. A model of a bilinear material was used with reinforcement following plasticizing. Additionally, stress in the $\mathrm{X}-\mathrm{X}$ axis of $\mathrm{Sx}=+167 \mathrm{MPa}$ was introduced in the model of the core.

An analysis provided an estimation of the "base" displacement for the core in the X-X axis, which initiates plasticizing strain around the inclusion. The analysis result is shown in Fig. 7.

The analysis shows that the core area perpendicular to the forcing is plasticized. The maximum of plasticizing strain is situated at the phase border. Therefore, as expected, decohesion may initially occur in the sphere of the core-inclusion contact, where the formation of a fatigue crack is supposed to start. This result is consistent with the findings of an experiment [3] which confirmed the reasonableness of the proposed method of observation (Fig. 3) (formation of pockets from which a fatigue crack is formed). The displacement that initiates such an effect was determined to be $\mathrm{Ux}=0.001 \mathrm{~mm}$.

\section{Case 2 - Inclusion in the layer formed by}

The same numerical model as previously was used in the analysis, with the yield limit of the core material and the stress in the $\mathrm{X}-\mathrm{X}$ axis changed so that the initial parameters corresponded to the "section" of a sublayer. A section of a hardened layer situated $0.4 \mathrm{~mm}$ from the surface was used

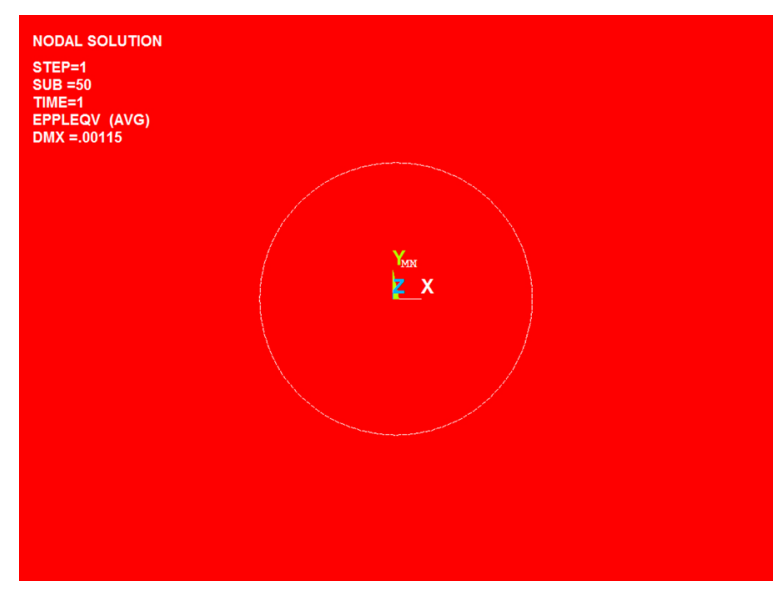

Fig. 8. Map of plastic strainaround the inclusion case 2 in the numerical calculation of FME. The yield limit for the area was determined to be $\mathrm{Re}=2090$ $\mathrm{MPa}$, and the stress in the core-sublayer in the $\mathrm{X}-\mathrm{X}$ axis resulting from the stress distribution in the top layer to be $\mathrm{Sx}=-350 \mathrm{MPa}$.

The model was forced with a displacement in the $\mathrm{X}-\mathrm{X}$ axis, whose value was determined to be 0.00115 . This value was estimated analytically taking into account the distribution of beam bending stress in the elastic area (Fig. 4). The analysis is shown in Fig. 8.

The analysis conducted with such a model showed that no plasticizing strains appeared around the inclusion. Although the yield limit of an inclusion is lower than that of the core, the stress occurring in the area of observation does not cause the formation of a potential site of initiation of a fatigue crack. Therefore, the analysis can explain the initiation of a fatigue crack under the hardened layer (comparing case 1 and 2), where the main role in the initiation of the a fatigue crack is played by the stress in the layer and the strength of the core, assuming that the yield limit of an inclusion is lower than that of the core.

\section{Case 3 - an inclusion on the surface of a hardened layer}

A model for FEM calculations was developed in the analysis presented below as in previous cases, with such a change that the inclusion itself is "half" of an inclusionas in previous calculations and is situated at the very surface of the "section" of a sublayer (Fig. 9). The boundary conditions for the analysis: yield limit of the sublayer $\mathrm{Re}=$ $2339 \mathrm{MPa}$, stress in the axis X-X Sx $=-706 \mathrm{MPa}$, displacement of a "section" along the X-X axis $\mathrm{Ux}=0.00125 \mathrm{~mm}$.

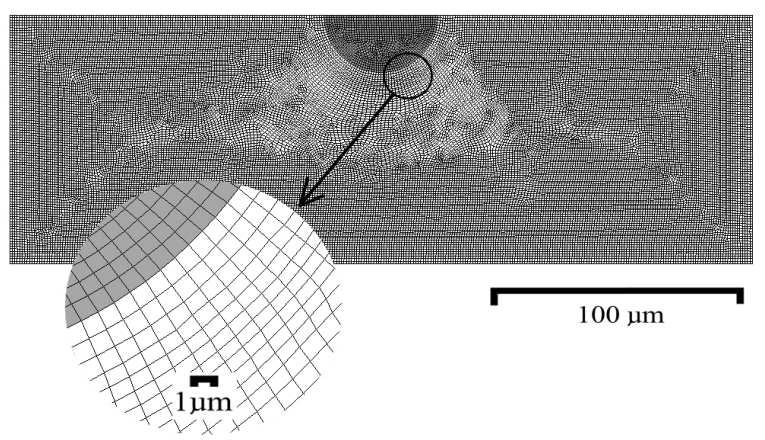

Fig. 9. Numerical model of inclusion on the surface - case 3 


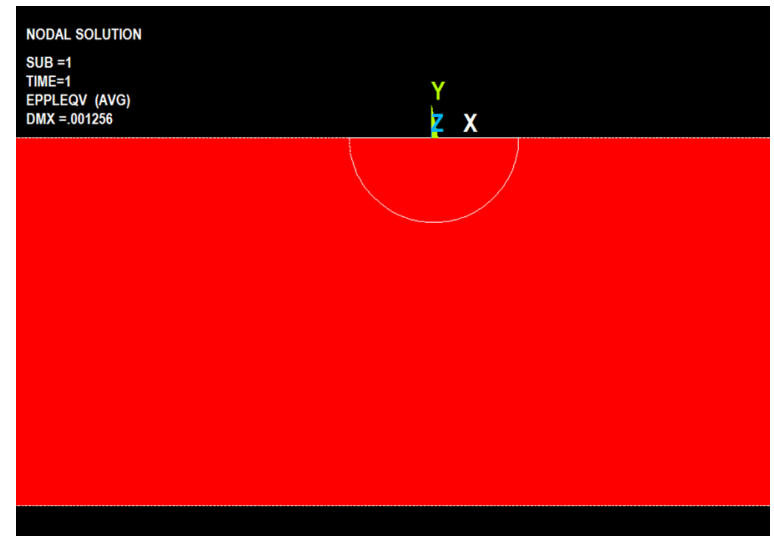

Fig. 10. Map of Sx plastic strainaround the inclusion - case 3

The distribution of plastic strains shows that inclusions - like in the previous case - do not generate plastic strain (Fig. 10). In both cases under analysis, when an inclusionis located in a hardened layer, where stress following the treatment is negative, a fatigue crack will not be initiated. It

a)

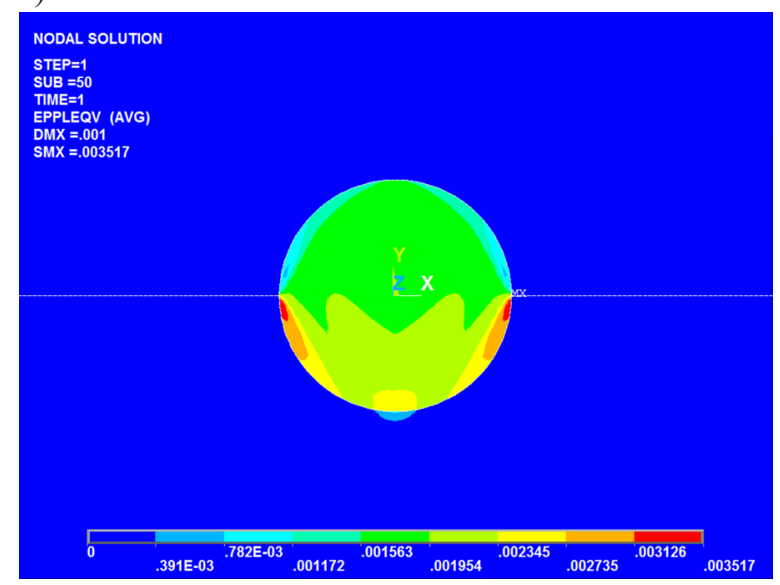

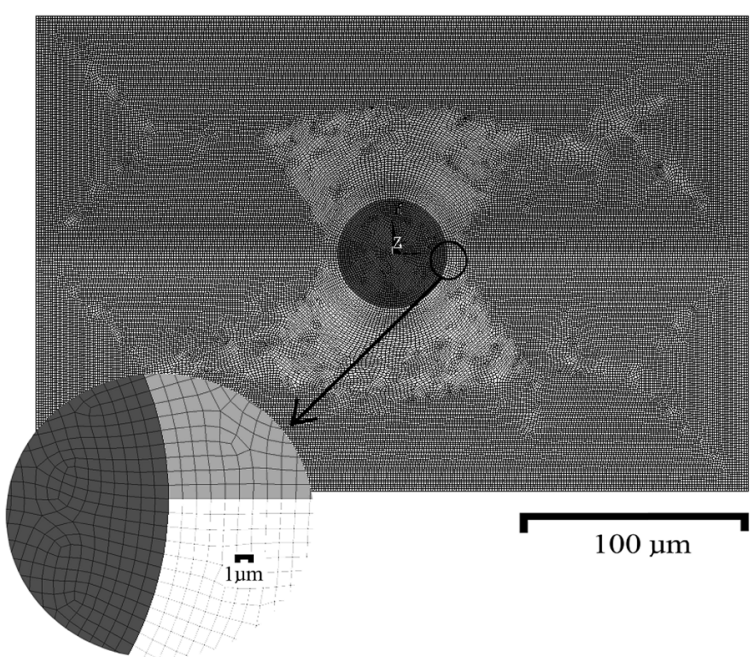

Fig. 11. A model of inclusion between two different areas

can be concluded from the numerical calculations conducted so far that an inclusion will initiate a fatigue crack in the core under the layer whereas under this load a crack would not open in a top layer hardened by TCT.

\section{Case 4 - inclusion between two areas of different initial levels of SX stress}

There is an interesting case of the effect of inclusion situated between areas of different initial SX stress, resulting from the distribution of stress in the top layer. A place situated between $0.7 \mathrm{~mm}$ and $0.8 \mathrm{~mm}$ from the surface was analyzed(Fig. 11). A numerical model was developed like in previous cases, with the initial residual stress was determined to be $\mathrm{Sx} 1=+20 \mathrm{MPa}$ for the upper

b)

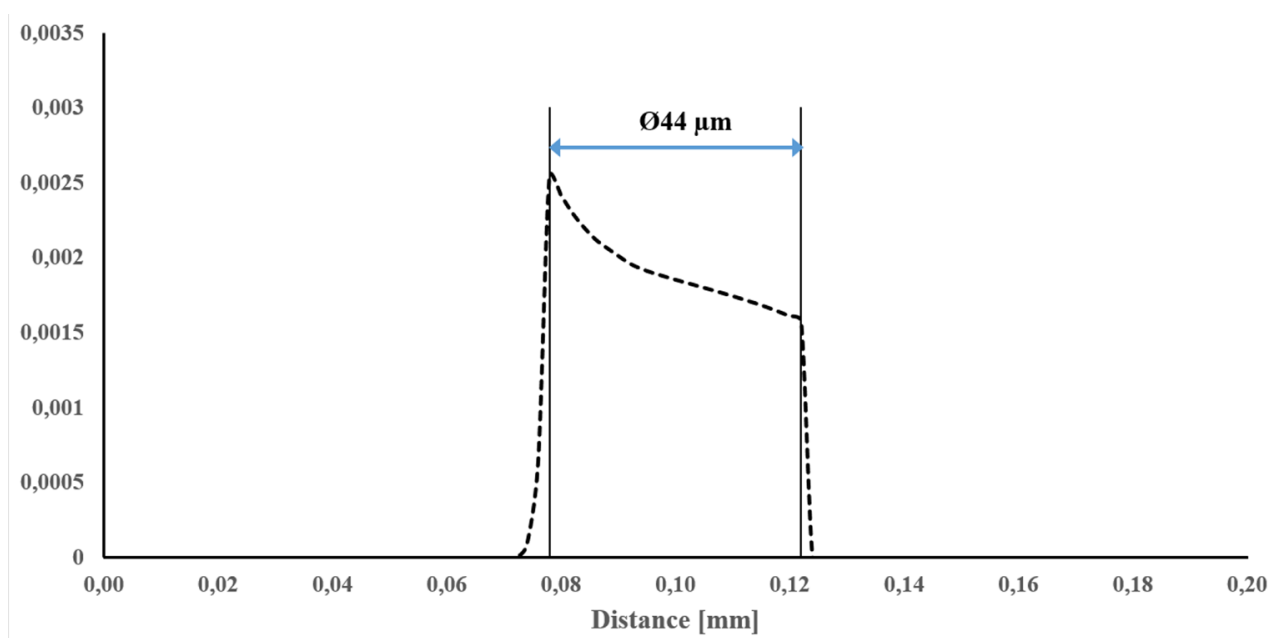

Fig. 12. a) A map of plasticizing strainaround the inclusion case 4 , b) a graph of plasticizing strain as a function of distance from the surface (a diameter of inclusion is determined) 
area and $\mathrm{S} \times 2=+167 \mathrm{MPa}$ for the lower area. The size of the inclusion is $44 \mu \mathrm{m}$, as before. As this section lies within the core, the yield limit was estimated to be $\operatorname{Re}=1052 \mathrm{MPa}$.

The analysis showed the maximum plastic strain in the lower part of the area under observation.

The observation showed that a fatigue crack canbe initiated in the area under the greatest load resulting from the distribution of stress in the $\mathrm{X}-\mathrm{X}$ axis of the top layer (Fig. 12). The maximum of the plasticizing strain lies on the side of the maximum positive stress in the layer. Therefore, destruction - and, consequently, the formation of a crack - will first occur on the side of the maximum plasticizing strains. Therefore, the mechanism of a fatigue initiation observed in this case confirms that such initiation in layers formed by TCT is caused by the distribution of residual stress resulting from technological treatment.

\section{CONCLUSIONS}

This numerical analysis showed that non-metallic inclusions whose yield limit is lower than that of the core are the cause of loss of structure integrity under external loads. This contributes to the formation of a fatigue crack. Such a phenomenon can be mainly observed in areas under a hardened layer. Moreover, the study also showed that the shape of the plasticized areas is largely comparable to the picture observed under a scanning microscope. A pocket is formed around an inclusion. Initially, it is a strongly plasticized area in which a void is formed in the next stage. Decohesion occurs at the border between two different structures, which results in the formation of a fatigue crack. However, initiation of the process of plasticizing the zones laying on the border of two structures (inclusion - matrix), as well as the further course of decohesion process between them, depends on the plasticizing stress distributions around the inclusion. In turn, the strain distribution around described inclusions depends on residual stresses distribution created in the technological surface layer after thermo-chemical treatment. The performed analysis shows that non-metallic inclusions present on the layer's surface, in the place of maximum compressive residual stress, do not cause fatigue initiation during cyclic bending stresses process. However, in the case of the same inclusion being under layer's surface in place of the maximum tensile residual stresses, it will become the main initiator of fatigue crack propaga- tion. Form the point of view of strain distribution it is the most dangerous place because in this region the concentration of plasticizing strains occurs, which was proven in performed FEM analysis. Therefore, comparing the FEM analysis results with research conducted by i.a. K. Dybowski et al. $[2,6]$ the non-metallic inclusions created as a result of steel deoxidation processare the cause of fatigue crack initiation as long as they are found in the place of maximum tensile stresses resulting from structural loading. Additionally, on the basis of presented research, it can be recognized that LPC treatment improves fatigue strength of structures because of big compressive stresses obtained on the layer's surface which limits fatigue process initiation. Such layer is resistant to the mentioned non-metallic inclusions influence.

\section{REFERENCES}

1. Dybowski K., Kula P., Lipa S., Pietrasik R. Bending fatigue strength determination of $17 \mathrm{CrNi} 6-6$ steel after low pressure carburising, Material Engineering, 31(4), 2010, 939-941.

2. Dybowski K., Kula P., Pietrasik R., Lipa S. Comparison of fatigue strength of 17CrNi6-6 and $16 \mathrm{MnCr} 5$ steel after vacuum,Material Engineering, 32(4), 2011, 392-394.

3. Dybowski K., Sawicki J., Kula P., Januszewicz B., Atraszkiewicz R., Lipa S. The effect of the quenching method on the deformations size of gear wheels after vacuum carburizing. Archives of Metallurgy and Material, 61(2B), 2016, 1057-1062.

4. Gawroński Z., Malasiński A., Sawicki J. Elimination of galvanic copper plating process used in hardening of conventionally carburized gear wheels. International Journal of Automotive Technology, 11(1), 2010, 127-131.

5. Gawroński Z., Sawicki J. Technological surface layer selection for small module pitches of gear wheels working under cyclic contact loads. Materials Science Forum, 513, 2006, 69-74.

6. Kula P., Dybowski K., Lipa S., Pietrasik R., Atraszkiewicz R., Klimek L., Januszewicz B., Wołowiec E. Investigating Fatigue Strength of Vacuum Carburized 17CrNi6-6 Steel Using a Resonance High Frequency Method. Solid State Phenomena,225, 2015, 45-52.

7. Kula P., Pietrasik R., Dybowski K. Vacuum carburizing - process optimization. Journal of Materials Processing Technology, 2005, 164-165.

8. Lei Z., Hong Y., Xie J., Sun Ch., Zhao A. Effects of inclusion size and location on very-high-cycle fatigue behaviour for high strength steels, Materials Science \& Engineering, A 558, 2012, 234-241. 
9. Lemaitre J. A Course on Damage Mechanics, Springer-Verlag, Berlin 1996.

10. Lis T., Różański P. Engineering of non-metallic inclusions in liquid steel, Metallurgist, Metallurgical News, 72(5), 2005, 259-264.

11. Niikura M, Yokota Y, Sato K, Shirota T. Ultra refinement of grain size and its effect on mechanical properties. Proceedings of the Workshop on New Generation Steel, 13-16 November. Beijing (China): The Chinese Society for Metals, 2001, 100-103.

12. Sakai T., Sato Y., Nagano N., Takeda M., Oguma $\mathrm{N}$. Effect of stress ratio on long life fatigue behavior of high carbon chromium bearing steel under axial loading, International Journal of Fatigue, 28, 2006, 1547-1554.

13. Sawicki J., Górecki M., Kaczmarek Ł., Gawroński Z., Dybowski K., Pietrasik R., Pawlak W. Increasing The Durability Of Pressure Dies By Modern Surface Treatment Methods. Chiang Mai Journal of Science, 40(5), 2013, 886 - 897.

14. Sawicki J., Kruszyński B., Wójcik R. The influence of grinding conditions on the distribution of residual stress in the surface layer of $17 \mathrm{CrNi6}-6$ steel after carburizing, Advances in Science and Technology Research Journal, 11(2),2017, 17-22.

15. Sozańska M. Hydrogen destruction type "fish eyes" selected steel for energetics, Academic Press Silesian University of Technology,1705, 2006.

16. Stachurski W., Zgórniak P., Sawicki J., Przybysz M. Hardening-related deformations of gear wheels after vacuum carburising and quenching in gas. Advances in Science and Technology Research Journal, 11(1), 2017, 237-245.

17. Wang QY, Berard JY, Bathias C et al. Gigacycle fatigue of ferrous alloys. Fatigue \&Fracture of Engineering Materials Structures, 22, 1999, 667.

18. Wang QY, Berard JY, Bathias C et al. High-cycle fatigue crack initiation and propagation behaviour of high-strength spring steel wires, Fatigue \&Fracture of Engineering Materials Structures, 22, 1999, 673.

19. Wang Q.Y., Bathias C., Kawagoishi N., Chen Q. Effect of inclusion on subsurface crack initiation and gigacycle fatigue strength, , International Journal of Fatigue, 24, 2002, 1269-1274.

20. Weng YQ. Development of ultrafine grained steels in China. In: Proceedings of the Workshop on New Generation Steel, 13-16 November, Beijing (China), The Chinese Society for Metals, 2001, 1-7.

21. Yang Z.G., Yao G., Li G.Y., Li S.X., Chu Z.M., Hui W.J.Dong H., Weng Y.Q. The effect of inclusions on the fatigue behavior of fine-grained high strength $42 \mathrm{CrMoVNb}$ steel, International Journal of Fatigue, 26, 2004, 959-966.

22. Zhou S, Murakami Y, Beretta S, Fukushima Y. Experimental investigation statistics of extremes for three-dimensional distribution of non-metallic inclusions. Materials ScienceTechnology,18, 2002, 1535-1543. 